\title{
UM ESTUDO DO ETHOS DISCURSIVO EM AUDIÊNCIAS DE CONCILIAÇÃO
}

\author{
Elaine Luzia da Silva ${ }^{1}$ \\ Leonardo Coelho Corrêa Rosado ${ }^{2}$ \\ Mônica Santos de Souza Melo ${ }^{3}$
}

Resumo: O presente artigo investiga as principais estratégias de construcão do ethos do sujeito enunciadorconsumidor que emergem na produção discursiva dos participantes de Audiências de Conciliação, de um Juizado Especial Civel de Relaçoes de Consumo de uma cidade mineira. Para tanto, selecionamos duas Audiências de Conciliação, que foram transcritas e analisadas a partir da teoria Semiolinguistica de Patrick Charaudeau. A análise dos dados demonstrou que, ao longo das audiências analisadas, o ethos de vítima do consumidor/reclamante é encenado através de algumas estratégias discursivas, as quais não são aleatórias; ao contrário, as estratégias utilizadas coadunam-se com o projeto de fala que o consumidor tem em mente e, sobretudo, ao ethos que ele procura encenar.

Palavras-chave: Audiências de Conciliação. Ethos discursivo. Semiolinguística.

\section{INTRODUÇÃO}

Em qualquer discurso, ao falarmos de outras pessoas ou de nós mesmos, há uma questão de seleção, já que muitas possibilidades de descrição são possíveis. Portanto, não há descrições neutras. Elas são ricas em inferências, categorizações, tendo em vista que fortes expectativas e convenções estão associadas a elas. Nossos discursos não somente nos proveem com rótulos que nos permitem referir a pessoas, mas também fornecem recursos inferenciais através dos quais podemos entender e interpretar o comportamento descrito e designado pelas pessoas.

\footnotetext{
${ }^{1}$ Mestranda em Letras/Linguística Aplicada ao Ensino de Línguas, Universidade Federal de Viçosa (UFV).Email: elaineufv@yahoo.com.br.

2 Mestrando em Letras/Estudos Discursivos, Universidade Federal de Viçosa (UFV); Bolsista CAPES/REUNI. Email: timtimcorre@hotmail.com.

${ }^{3}$ UFV; Professora Associada I; Doutora em Estudos Linguísticos/Análise do Discurso, UFMG. Email: monicassmelo@yahoo.com.br.
} 
Dessa forma, qualquer ato de linguagem implica a construção de uma imagem de si no discurso e essa imagem pode ser positiva ou negativa dependendo da influência que o locutor deseja exercer em seu interlocutor no momento da enunciação. Assim, uma pessoa pode querer construir uma imagem de pessoa boa, ingênua, inteligente, malvada, exigente, etc. dependendo do seu propósito. Para isso, conforme explicita Amossy (2005a), não é necessário que o locutor faça seu autorretrato, fale explicitamente suas qualidades ou defeitos, pois, no momento do discurso, o locutor dá algumas dicas sobre o seu "eu" que são suficientes para criar uma representação de si. Essa imagem, de si mesmo ou do outro, construída no discurso, tem sido chamada de ethos discursivo.

Neste artigo, apresentamos resultados de um estudo da construção do ethos discursivo de consumidores participantes de Audiências de Conciliação de um Juizado Especial Cível de Relações de Consumo. Esses juizados são responsáveis por causas de menor complexidade, que não ultrapassem o valor de quarenta salários mínimos. Para marcar uma audiência, não é preciso que o consumidor apresente provas documentais. Basta que ele apresente sua reclamação oralmente ou por escrito para que a data da audiência seja agendada. Além disso, em casos abaixo de vinte salários mínimos, a assistência de advogado é facultativa; nessas situações, os próprios participantes das audiências advogam em causa própria. Nesse órgão do poder judiciário, prevalecem a oralidade, a gratuidade e a conciliação como meta.

Nosso objetivo com este trabalho é analisar e descrever as estratégias de construção do ethos discursivo em duas Audiências de Conciliação gravadas em agosto de 2008 na cidade de Belo Horizonte/MG, utilizando como instrumental teórico-metodológico a Teoria Semiolinguística de Patrick Charaudeau, conjugado ao conceito de ethos discursivo.

O presente artigo está dividido em três seções, além desta introdução e das palavras finais. $\mathrm{Na}$ primeira seção, apresentaremos a noção de ethos considerando a sua dimensão histórica (Antiguidade Clássica) e seu atual uso na análise do discurso. Em seguida, 
apresentaremos o conceito no âmbito da Teoria Semiolinguística, já que ela é a base deste trabalho. Na segunda seção, descreveremos as audiências de conciliação e o contrato comunicacional subjacente a essa situação de comunicação. Já na terceira seção, analisaremos as audiências selecionadas, observando as principias estratégias de construção do ethos e a recorrência do tipo de ethos encenado na situação comunicativa em estudo.

\section{O CONCEITO DE ETHOS}

\subsection{O ETHOS NA ANTIGUIDADE CLÁSSICA}

A noção de ethos (do grego $\eta \theta \dot{s}$, personagem) é um conceito que remonta à Antiguidade clássica e designa, conforme aponta Amossy (2005a), a imagem de si que o locutor constrói em seu discurso para exercer certa influência em seu alocutário. Sobre o ethos, Aristóteles (2007) aponta que:

O caráter [ethos] pessoal do orador alcança a persuasão, quando ele nos leva a crer no discurso proferido. Acreditamos mais nos homens de bem por serem mais preparados e íntegros do que outros. Em geral, isso é verdadeiro, qualquer que seja a questão, e absolutamente verdadeiro onde a certeza exata é impossível e as opiniões estejam divididas. Assim como as demais, essa espécie de persuasão será alcançada por aquilo que é dito pelos oradores, e não pelo que o povo pensa a respeito do seu caráter antes do início do discurso (ARISTÓTELES, 2007, p. 23-24).

$\mathrm{Na}$ Antiguidade, o ethos é definido a partir de duas posições: de um lado, há aqueles que o entendem como um dado preexistente ao discurso. É o caso de Isócrates, Cícero e outros retóricos; de outro lado, há aqueles para quem o ethos é um dado discursivo, no qual o orador produz uma imagem de si no seu próprio discurso. Nesta última filiação, encontramos Aristóteles, que postula, em sua Retórica, que o ethos, juntamente com o pathos e o logos, é um dos meios de prova utilizados 
pelo orador para a eficácia de seu discurso4. Ao longo da tradição retórica, essas duas tendências se consolidaram em duas definições para o termo. Assim, podemos dizer, como Amossy (2005b) que, há, desde a Antiguidade Clássica, um conceito de ethos entendido como ethos prévio, e um outro conceito de ethos compreendido como ethos discursivo.

\subsection{O ETHOS NA ANÁLISE DO DISCURSO}

No que concerne à Análise do Discurso, Maingueneau, de acordo com os apontamentos de Amossy (2005a), é o primeiro a utilizar o termo e também a associá-lo a um ponto de vista estritamente discursivo. Para Maingueneau (2005, p.69), o ethos está ligado ao processo mais geral de adesão dos sujeitos a uma certa posição discursiva, distinguindo-se de outros meios de persuasão, como a persuasão por argumentos. O ethos, em sua teoria de análise do discurso, se manifesta não somente como um papel linguageiro e um estatuto social, isto é, como uma posição institucional marcada por um saber que o sujeito encena através de seu discurso, mas também como uma voz (tom) e como um corpo enunciante, corporificado através do processo de incorporação.

Todo discurso possui uma vocalidade específica (voz) que, por meio de um tom, remete-se a uma fonte enunciativa. Essa vocalidade específica implica uma corporalidade específica, o corpo do enunciador. Assim, todo discurso faz emergir uma origem enunciativa, uma instância subjetiva encarnada que exerce o papel de fiador, de garantia do dizer. É por isso que em Maingueneau (2005) o ethos recobre não somente a dimensão vocal, mas também o conjunto de determinações físicas e psíquicas que são atribuídas à personagem do orador pelas representações coletivas. Dessa forma, o fiador está dotado tanto de um caráter (feixe de traços psicológicos) quanto de uma corporalidade (compleição corporal, forma de vestir-se e mover-se no espaço social).

\footnotetext{
${ }^{4}$ Para uma melhor compreensão do conceito do ethos aristotélico, ver o artigo de Ekkehard Eggs (2005), Ethos aristotélico, convicção e pragmática moderna.
} 
Caráter e corporalidade constituem as duas dimensões do ethos na Teoria de análise do discurso de Maingueneau.

Maingueneau (2005) ainda nos esclarece que o ethos estabelece uma relação entre o discurso e o destinatário através do processo de incorporação. Esse processo se dá em três dimensões:

a) A enunciação dá corpo ao seu enunciador - que exerce o papel de fiador (de uma fonte legitimante) -, permitindo que o destinatário construa uma fonte dinâmica dele;

b) O destinatário, então, incorpora (lê-se "assimila") os esquemas característicos desse fiador, a sua maneira de habitar o corpo e de se mover no mundo;

c) Os dois processos anteriores permitem a incorporação do destinatário à comunidade imaginária dos que aderem a um mesmo discurso.

Embora o ethos em Maingueneau seja uma dimensão discursiva, uma vez que está ligado à enunciação, ele admite que as duas dimensões do ethos, caráter e corporalidade, se apoiem no conjunto das representações sociais, dos estereótipos que circulam em uma dada comunidade. Assim:

Caráter e corporalidade do fiador apoiam-se, então, sobre um conjunto difuso de representações sociais valorizadas ou desvalorizadas, de estereótipos sobre os quais a enunciação se apoia e, por sua vez, contribui para reforçar ou transformar. Esses estereótipos culturais circulam nos registros mais diversos da produção semiótica de uma coletividade: livros de moral, teatro, pintura, escultura, cinema (MAINGUENEAU, 2005, p. 72).

Logo, ele admite um ponto de vista pré-discursivo no ethos (que ele denomina ethos pré-discursivo), que funciona como uma ancoragem do discurso em termos de interdiscurso. Além disso, pelo fato de o ethos estar ligado à enunciação, isso permite distinguir o ethos dito, ethos pelo qual o enunciador diz quem ele é em seu enunciado, do ethos mostrado, ethos pelo qual o enunciador mostra como ele é através de sua enunciação. Portanto, em Maingueneau (2005 e 2008), o ethos é 
resultante da interação de diversos elementos: a) do ethos pré-discursivo, b) do ethos discursivo, c) do ethos dito e d) do ethos mostrado. A figura 1 nos dá clareza quanto a essa questão:

Figura 1 - A constituição do ethos em Maingueneau:

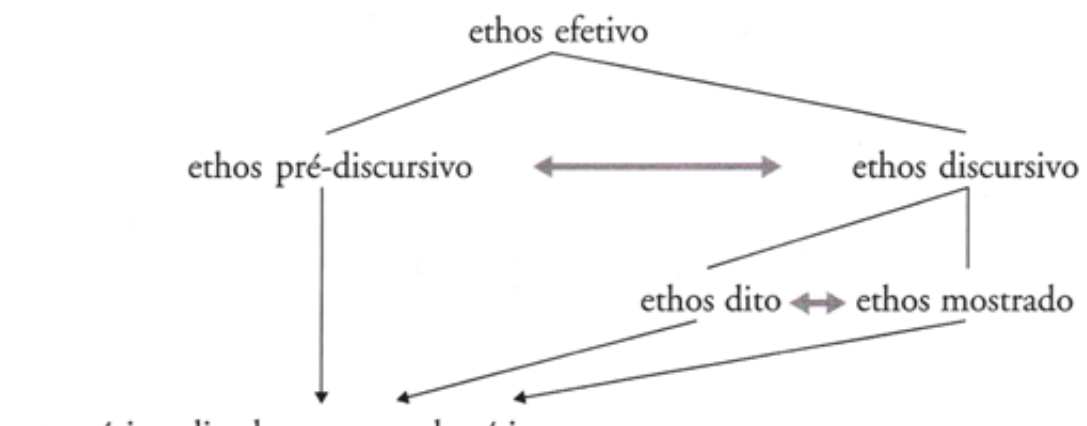

estereótipos ligados aos mundos éticos

\section{Fonte: Maingueneau (2008).}

Essa concepção de ethos que apresentamos aqui foi constituída por Maingueneau ao longo de vários trabalhos. Em uma de suas últimas publicações, intitulada A propósito do ethos, o analista do discurso acrescenta ao ethos a noção de "mundo ético". Segundo Maingueneau (2008), a instância subjetiva encarnada, o fiador, constituída a partir do processo de incorporação, sempre implica um "mundo ético" do qual ele é parte pregnante e ao qual ele dá acesso. Assim, para ele, esse "mundo ético", ativado pela leitura do discurso, corresponde a um certo número de situações estereotípicas associadas a comportamentos.

No âmbito da AD, outros autores, como Amossy (2005b), também consideram o ethos em uma perspectiva discursiva, porém admitindo nele uma dimensão pré-discursiva. No caso de Amossy (2005b), ela considera que a dimensão pré-discursiva do ethos, denominada ethos prévio, constitui-se como um elemento da doxa, ou seja, como parte de um conjunto de crenças e opiniões partilhadas entre os sujeitos, que fundamentam e autorizam a interação verbal. Para ela, o 
orador modela o seu ethos em função das representações coletivas que tanto ele quanto o auditório partilham. Assim, a imagem do orador se constrói a partir da imagem que ele faz do auditório, isto é, das representações de orador competente e digno de fé que ele crê ser a do auditório.

\subsection{O ETHOS NA TEORIA SEMIOLINGUÍSTICA DO DISCURSO: O PROCESSO DE IDENTIFICAÇÃO OU DE CONSTRUÇÃO DE UMA IMAGEM DE SI}

No âmbito da Teoria Semiolinguística do Discurso, o processo de construção de uma imagem de si no ato de linguagem é denominado processo de identificação (ver figura 2). Tal processo remete-se ao ethos da tradição retórica e diz respeito não somente ao autorretrato que o enunciador faz a partir de seu dizer, mas, sobretudo, de seu estilo, de sua competência linguística e enciclopédica e de suas crenças implícitas, que são suficientes para construir uma representação de sua pessoa, bem como da imagem prévia do sujeito comunicante que circula no seu grupo social. Essa representação, essa imagem construída no e pelo discurso, facilita a realização do projeto de fala do sujeito enunciador (EUe)5, uma vez que ela permite que o locutor seja julgado e avaliado pelo destinatário como digno de crédito.

Dessa maneira, para Charaudeau (2006), o ethos constitui-se como um dos processos linguageiros diante dos quais o enunciador é colocado quando ele toma a palavra para influenciar o seu destinatário. A figura 2 evidencia quais são os processos linguageiros que o enunciador tem diante de si quando ele inicia o ato de linguagem:

\footnotetext{
${ }^{5}$ As siglas EUc, EUe, TUd, TUi correspondem, no âmbito da Teoria Semiolinguística, aos sujeitos que compõem o ato de linguagem: sujeito comunicante (EUc), sujeito enunciador (EUe), sujeito destinatário (TUd) e sujeito interpretante (TUi).
} 
Figura 2 - Os quatro processos de tomada de palavra:

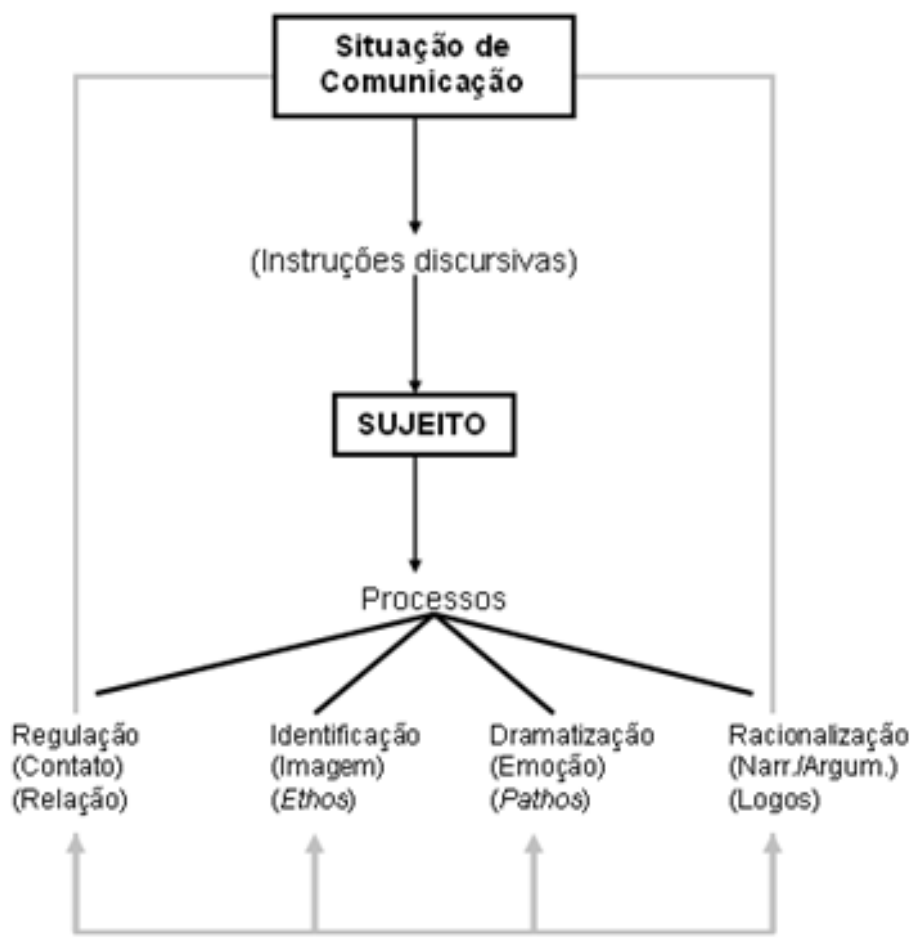

Fonte: Charaudeau, 2008a.

Além da imagem encenada através do discurso, o processo de identificação vale-se ainda da imagem prévia do sujeito-comunicante que circula no grupo social ao qual ele pertence. Logo, Charaudeau (2006), assim como Maingueneau (2005, 2008) e Amossy (2005b), também admite que o ethos possui uma dupla dimensão: uma dimensão discursiva, denominada ethos discursivo ou ethos construído, e uma dimensão pré-discursiva, denominada ethos pré-construído. Assim, Charaudeau (2006) entende o ethos da seguinte forma: 
De fato, o ethos, enquanto imagem que se liga àquele que fala, não é uma propriedade exclusiva dele; ele é antes de tudo a imagem de que se transveste o interlocutor a partir daquilo que diz. O ethos relaciona-se ao cruzamento de olhares: olhar do outro sobre aquele que fala, olhar daquele que fala sobre a maneira como ele pensa que o outro o vê. Ora, para construir a imagem do sujeito que fala, esse outro se apoia ao mesmo tempo nos dados preexistentes ao discurso - o que ele sabe a priori do locutor - e nos dados trazidos pelo próprio ato de linguagem (CHARAUDEAU, 2006, p. 115).

A noção apresentada dialoga com o esquema enunciativo que Charaudeau (2008b) propõe para compreender o ato de linguagem, ou seja, a noção de ethos proposta volta-se para a questão da identidade do sujeito falante desdobrada em dois componentes. Assim, temos que o ethos pré-construído liga-se à identidade do sujeito como ser psicossocial; em outras palavras, o ethos pré-construído é um dado que remete ao sujeito comunicante (EUc) do ato de linguagem. Já o ethos discursivo dialoga com a identidade do sujeito enquanto ser discursivo, ou seja, enquanto sujeito enunciador (EUe). Neste sentido, o sujeito que enuncia constrói para si uma identidade discursiva que se atém aos papéis que ele atribui a si próprio em seu ato de linguagem, conforme coerções impostas pela situação de comunicação, e pelas estratégias que ele, enquanto sujeito enunciador, escolhe seguir.

Nesse sentido, podemos entender que o locutor constrói seu ethos discursivo em função de seu ethos pré-construído: ele tenta consolidá-lo, retificá-lo, retrabalhá-lo ou atenuá-lo.

Portanto, a imagem do sujeito falante, ou locutor, isto é, o seu ethos, aparece ao seu interlocutor como uma identidade psicológica e social que lhe é atribuída e, ao mesmo tempo, como uma identidade discursiva construída por ele para a eficácia de seu discurso. Desta forma, o sentido que o locutor veicula em suas palavras para identificarse (processo de identificação) depende daquilo que ele é, enquanto ser psicossocial, e daquilo que ele diz enquanto ser discursivo; e o ethos, como resume Charaudeau (2006), é essa dupla identidade que termina por se fundir em uma só. 


\section{O CONTRATO DE COMUNICAÇÃO DAS AUDIÊNCIAS DE CONCILIAÇÃO: ALGUNS APONTAMENTOS}

Para compreendermos o processo de identificação, isto é, o ethos do enunciador, a partir dos pressupostos teórico-metodológicos da Teoria Semiolinguística, é necessário, como pudemos visualizar na figura 2, considerarmos a situação de comunicação em que tal processo ocorre, uma vez que tal situação emite instruções discursivas que, de certo modo, incidem nos processos de tomada de fala, dentre eles o processo de identificação, nosso alvo de análise.

No âmbito da Teoria Semiolinguística, uma situação de comunicação define-se a partir de um contrato comunicacional que liga os parceiros da troca comunicativa em termos de uma finalidade enunciativa. Assim, o contrato de comunicação é o conjunto de restrições que codificam as práticas sociolinguageiras, resultando nas condições de produção e interpretação do ato de linguagem. Tais restrições, denominadas restrições contratuais, tocam nos seguintes componentes:

a) finalidade, categoria que ordena o ato de linguagem em função de um objetivo;

b) identidade, componente que depende diretamente dos sujeitos que se acham inscritos e engajados na troca linguageira, definindo-os em termos de traços da natureza social e traços do status social;

c) propósito, categoria que requer que todo ato de linguagem seja construído em torno de um domínio de saber; e

d) circunstâncias materiais, ou condições materiais da comunicação, que constituem o dispositivo material em que o ato de linguagem se realiza.

A situação de comunicação selecionada para este trabalho constitui-se de Audiências de Conciliação, uma situação pertencente ao domínio jurídico e que possui um contrato de comunicação do tipo jurídico.

As Audiências de Conciliação são sessões coordenadas por mediadores/conciliadores cuja finalidade contratual é a de promover um acordo entre os participantes. Tais conciliadores são os responsáveis por ouvir os participantes da troca (a saber, o consumidor/reclamante e o 
fornecedor/reclamado) e, a partir de então, empenhar-se na tentativa de um acordo e numa finalização antecipada do processo. Logo, seu papel na encenação discursiva é o de mediar a audiência com o intuito de se chegar a um acordo entre as partes. O ideal, durante o desenvolvimento de uma audiência desse tipo, é que o mediador não crie vínculos com nenhuma das partes para que ele se mantenha o mais imparcial possível, dada a objetividade que requer o contrato de comunicação dessa situação jurídica.

Os sujeitos envolvidos nessa situação de comunicação são normalmente o consumidor/reclamante, o qual tem o direito de narrar primeiramente os fatos ocorridos; o fornecedor/reclamado, que tem a função de fazer uma proposta ao consumidor, a partir da qual o acordo será negociado; e o mediador/conciliador, que não possui poder de decisão. Na verdade, ele conta apenas com suas habilidades argumentativas para tentar uma reelaboração da situação e, assim, promover o acordo entre os parceiros.

Com frequência, as Audiências de Conciliação iniciam-se com o mediador se apresentando e deixando claro que o objetivo da audiência é o acordo. Feito isso, ele aloca o turno ao consumidor para que este relate a história do conflito. Após a fala do consumidor, o mediador dá o direito à palavra ao reclamado, dando a este a oportunidade de contar sua versão dos fatos e fazer uma proposta de acordo. Portanto, devido à explícita troca de turnos entre os parceiros, as Audiências de Conciliação são situações dialogais cujos parceiros estão presentes fisicamente, isto é, uma situação cuja configuração verbal do ato de linguagem do sujeito enunciador (EUe) comporta particularidades como:

a) uma ordem de palavras afetivas, que coloca em primeiro lugar os elementos de informação julgados (ou sentidos) como os mais importantes pelo locutor;

b) uma construção segmentada das sequências de palavras quase sem ligações lógicas; e

c) uma alternância de turnos (CHARAUDEAU, 1992, p. 639).

Em grande parte das audiências, não há a presença de um advogado, visto que sua presença não é obrigatória em audiências em 
que o valor negociado situa-se abaixo de vinte salários mínimos; dessa forma, os participantes advogam em causa própria. Quando o consumidor responde ao pedido inicial do mediador para contar a história do conflito, implicitamente está um pedido de explicação sobre a sua presença no juizado e o motivo de sua reclamação. Assim, nesse momento o consumidor tem a oportunidade de tentar convencer $\mathrm{O}$ mediador de que o seu caso é realmente grave e a sua reclamação justa. Logo, nesse momento inicial da Audiência, o sujeito consumidor pode se valer de várias estratégias argumentativas para persuadir o mediador e também o reclamado. Dessa forma, tal sujeito pode procurar encenar um ethos que vá ao encontro de seu empreendimento argumentativo, fazendo legítima sua reclamação.

Portanto, em termos contratuais, a Audiência de Conciliação é uma situação pertencente ao domínio jurídico, cuja finalidade é levar os sujeitos envolvidos, as denominadas partes (consumidor/reclamante, fornecedor/reclamado), a um acordo, sendo a interação entre tais sujeitos mediada pelo conciliador/mediador, que não possui poder de decisão, mas cujo papel linguageiro é o de mediar a troca entre os participantes e levá-los a concretizar um acordo. O propósito é bastante variado, mas tais situações sempre levam em conta causas jurídicas inferiores a quarenta salários mínimos. No que diz respeito ao dispositivo de comunicação, observamos que os sujeitos estão presentes fisicamente, sendo eles, na grande maioria das vezes, únicos (a não ser quando há a presença de advogados, que representam as partes); eles utilizam prioritariamente o canal oral, caracterizando, portanto, uma situação dialogal com explícita troca de turnos.

\section{ANALISANDO OS DADOS: O ETHOS DISCURSIVO NAS AUDIÊNCIAS DE CONCILIAÇÃO}

O corpus de nosso trabalho constitui-se de duas audiências de conciliação gravadas em agosto de 2008, na cidade de Belo Horizonte/MG. Foram gravadas em áudio (fita cassete) e depois transcritas para, em seguida, ser realizada a análise a partir do arcabouço teórico-metodológico selecionado. 
Nesta seção, faremos uma breve apresentação de cada audiência, seguida de sua análise, separadamente. $\mathrm{Na}$ análise, procuraremos descrever, como já apontado em nossa introdução, as principais estratégias de construção do ethos utilizadas pelos sujeitos consumidores/reclamantes da situação de comunicação nomeada como Audiências de Conciliação. Por se tratar de uma situação dialogal, marcada pela explícita troca de turnos, os sujeitos enunciadores mudam ao longo do ato. Dessa forma, o foco de nossa análise será o ato de linguagem pelo ponto de vista do enunciador-consumidor. Em seguida, faremos uma análise conjunta das duas audiências analisadas, de forma a verificar qual ethos é recorrente em ambas.

Em concordância com os princípios éticos envolvidos em uma pesquisa desta ordem, foi solicitado aos participantes seu consentimento para participarem dela; a fim de proteger suas identidades, os nomes apresentados são fictícios, assim como os nomes das empresas envolvidas.

\subsection{AUDIÊNCIA (1): BANCO POUPA FÁCIL}

Participaram dessa audiência: a consumidora (Ana), a mediadora (Cristina), o advogado da consumidora (Marcelo), a representante do banco (Mara) e a advogada do banco (Rita). O que motivou essa audiência foi a insatisfação da consumidora com um determinado banco - aqui ficticiamente chamado de Banco Poupa Fácil - por a consumidora ter cortado o seu dedo no momento em que fazia um depósito em um caixa de autoatendimento. A consumidora reivindica uma indenização por danos morais, alegando que o banco não lhe prestou nenhum socorro; o banco, por sua vez, nega o pedido de indenização e deseja contestar a reclamação da consumidora. Portanto, não foi possível uma conciliação.

Como mencionamos anteriormente, as Audiências de Conciliação são situações de comunicação marcadas pela troca de turnos entre os parceiros da interação linguageira, isto é, trata-se de uma situação comunicativa dialogal. Além disso, ao tomar a palavra, o 
consumidor/reclamante se dirige diretamente ao conciliador/mediador e, indiretamente, ao fornecedor/reclamante. Dessa forma, ao alocar o turno e iniciar seu ato de linguagem, o consumidor/reclamante assume o papel de sujeito enunciador (EUe) deste ato e cria uma imagem do conciliador/mediador, bem como do fornecedor/reclamante como sendo o sujeito suscetível de ser persuadido pelo seu projeto de fala, ou seja, estes últimos sujeitos tornam-se o sujeito destinatário (TUd) do ato de linguagem do consumidor/reclamante. Tal ato de linguagem pode ser assim representado:

\section{Figura 3 - Quadro Enunciativo:}

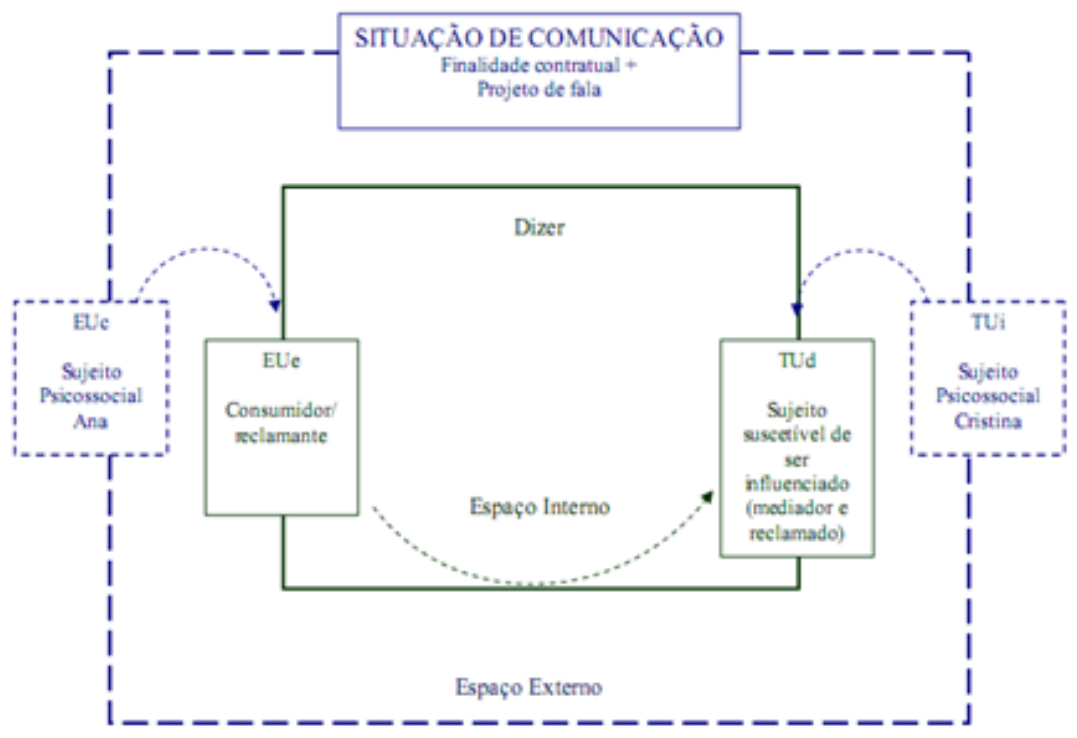

Fonte: Elaboração própria.

Como sujeito enunciador (EUe) do ato de linguagem, o consumidor/reclamante insere seu dizer em uma problemática de influência, na qual ele pretende levar o seu sujeito destinatário a certos fazeres: a um fazer crer, a um fazer aderir e a um fazer emocionar. No 
caso da audiência analisada, o sujeito enunciador narra que ele sofreu um dano físico após realizar um depósito no caixa de autoatendimento do Banco Poupa Fácil e que, devido a esse dano, outros prejuízos lhe ocorreram: gastos com empregada, impossibilidade de trabalhar como desenhista (sua profissão), gastos com medicamentos, etc. Através desta narrativa, o EUe tenta influenciar o seu destinatário a fim de que ele compartilhe a ideia de que seu caso merece atenção e de que o ressarcimento é justificado. Logo, ele realiza os processos de tomada de palavra que apresentamos nas seções anteriores (ver figura 2): a) processo de regulação, b) processo de identificação, c) processo de dramatização e d) processo de racionalização.

No que tange ao processo de identificação, processo este que permite a encenação do ethos do sujeito enunciador, observamos que o EUe, no seu papel de consumidor/reclamante, constrói, no momento inicial da audiência, um ethos de vítima, isto é, uma imagem em que ele se coloca como alguém que sofreu um prejuízo - no caso, um corte no dedo ao fazer um depósito em um dos caixas de autoatendimento do Banco Poupa Fácil - e, por isso, deve ser ressarcido. Vejamos exemplos (1) e (2):

\begin{tabular}{|ll|}
\hline $\begin{array}{l}\text { Cristina } \\
\text { Ana } \\
\text { Cristina }\end{array}$ & Vamos lá, Ana, conta pra gente o que aconteceu. \\
& Aconteceu.. que eu fui fazer um simples depósito no banco... \\
& $\quad(1.09)$ \\
Ana & e:: lá no banco: existe: um sistema de: aaautoatendimento.. \\
& que você só coloca.. o envelope, não pega recibo, não pega \\
& nada. Só: uma caixa de correio \\
& e coloca o envelope. Então eu sim:plesmente coloquei o \\
& envelope. \\
Cristina & ã? \\
Ana & e a tampa... prendeu meu dedo.../né?/ \\
Cristina & Qual dedo? \\
Ana & Esse aqui, esse. o vendo.. o corte? \\
Cristina & Tá \\
& Uma cicatriz aqui. E eu num o sentindo essa parte do dedo \\
& até hoje. E: foi um: transtorno pra mim, né? Ficar com esse: \\
Ana & com esse dedo esse tempo todo. Na outra audiência... tinha:: \\
& só uma se-uma: uma semana e pouca que.. já tinha \\
& cicatrizado. Eu tive complicações e tudo e foi uma \\
& coisa..traumatizante.. né? \\
\hline
\end{tabular}




\begin{tabular}{|ll|}
\hline Ana & eu coloquei o envelope.. e saí desesperada, ensanguentada \\
& porque eu achei até que tinha perdido a \\
Cristina & $(1.02)$ \\
& hum? \\
Ana & Porque o corte foi profundo, né? \\
& eu achei que- só via sangue, achei que aquilo tivesse até: \\
& cortado a ponta do dedo toda.. e fiquei parada e falei assim \\
& >“ai meu Deus! meu Deus! meu Deus!"< \\
& Diz ela até, depois eu tive lá depois, diz ela até que foi no \\
& fundo da agência pra procurar uma pessoa... mas.. ela \\
Ana & desapareceu e ninguém \\
& (1.09) \\
& me prestou socorro \\
& e ainda fiquei parada lá dentro do banco sem saber o que \\
Cristina & fazer= \\
& $=$ ã? \\
Ana & Meu marido tava parado ..com o carro.. na porta \\
Cristina & o que fiz foi.. correr até ele \\
& Sei \\
& corri até ele.. e tal \\
& e ainda fiquei ali na-na na calçada durante um tempo... \\
Ana & e surgiu gente para trazer papel higiênico \\
Cristina & pra trazer.. maço de:de: algodão \\
Ana & veio socorro de todo lado \\
& Do banco:: \\
& Do banco (1.14) ninguém.
\end{tabular}

A partir dos exemplos, percebemos que o ethos de vítima é construído pelo sujeito enunciador. Como o seu projeto de fala visa fazer crer ao destinatário que ele sofreu um prejuízo físico, visto que uma parte do seu corpo - o dedo - teve uma lesão causada pelo caixa de autoatendimento do Banco, construir um ethos de vítima coaduna-se com esse projeto. Assim, através do processo de identificação, o EUe reforça seu ato de influência e delineia parte de seu empreendimento argumentativo.

Ao longo do primeiro momento da audiência em questão, observamos que tal ethos de vítima é encenado por meio de algumas estratégias discursivas. A primeira concerne à narrativa que a enunciadora constrói ao longo do ato de linguagem. Ao narrar o que lhe havia acontecido, a consumidora o faz de forma bastante persuasiva a fim de convencer a mediadora (e, consequentemente, o fornecedor/reclamante) de que tal episódio não foi um simples 
incidente, mas algo grave. Nesse sentido, a narrativa da enunciadora é o resultado do emprego do modo de organização narrativo e, portanto, refere-se ao processo de racionalização que constrói o logos do discurso.

De acordo com Charaudeau (2008a), o processo de racionalização diz respeito à ordenação do dizer de forma a influenciar o destinatário. Assim, ao narrar o fato, o EUe insere-o em perspectiva de influência enunciativa: ele pretende fazer crer ao destinatário que o ocorrido foi bastante grave e que trouxe consequências negativas à sua vida pessoal. Porém, o modo como a narrativa é construída permite-nos observar o processo de identificação agindo concomitantemente ao processo de racionalização narrativo/descritivo. Dessa forma, consideramos a narrativa como uma estratégia, já que ela narra o fato de forma a construir o ethos do sujeito enunciador.

Ao longo da narrativa, há momentos cruciais que evidenciam o ethos que ela encena. Consideremos os exemplos (3) e (4) para visualizar tais momentos:

\begin{tabular}{|ll|}
\hline Cristina & Prendeu seu dedo \\
Ana & Prendeu meu dedo \\
Cristina & E você tev- você foi pro João 23? \\
Ana & /Isso/, fui pro João 23 \\
Cristina & $\tilde{\text { Â? }}$ \\
Ana & Levei sete pontos.. depois que eu tirei os pontos... teve uma \\
& complicação porque: inflamo:u, teve:: num-num tinha \\
& fechado. \\
& Inclusive essa foto eu tirei...depois de tirar os pontos (2.46) \\
& Foram: dois meses assim \\
\hline
\end{tabular}

(4)

Ninguém procurou saber.. o que que aconteceu realmente e
tal.. eu fui.. pro pronto socorro direto, meu marido- porque é
perto do pronto socorro o banco
meu marido me levou lá, levei sete pontos.
E::depois disso só transtorno, né?
Sem poder molhar a mão... aquela coisa tenho- eu trabalho
com desenho
Minha:: tenho três filhos, não tenho empregada.
imaginou?
/o transtorno?/


No exemplo (4), o EUe acusa o banco de não the ter prestado assistência e afirma ter sido encaminhado ao hospital pelo seu marido. Em seguida, ele afirma ter levado sete pontos e, assim, enfatiza a profundidade do ferimento. A fim de relatar as consequências que a lesão acarretou em sua vida e os prejuízos que teve em razão do acidente, o sujeito enunciador esclarece que, por ser desenhista, ficou impossibilitado de trabalhar. Além disso, ele afirma ter três filhos e não ter empregada; com isso, evidencia a dificuldade que teve em cuidar de seus filhos e fazer as tarefas domésticas com o dedo lesionado e, mais uma vez, a consumidora cria uma imagem de coitada, sofrida, enfim, de vítima.

Outra estratégia refere-se ao uso do comportamento elocutivo nesta mise en scène. Charaudeau (1992) aponta que através do comportamento elocutivo o locutor enuncia seu ponto de vista sobre o mundo, resultando, com isso, em uma enunciação que tem o efeito de modalizar subjetivamente a verdade contida no propósito referencial. $\mathrm{Na}$ audiência do Banco Poupa Fácil, o EUe utiliza esse comportamento enunciativo para mostrar o seu ponto de vista em relação ao fato narrado: ele deseja mostrar-se como vítima da situação, modalizando subjetivamente seu dizer. Consideremos os exemplos (5), (6) e (7):

eu num tô sentindo essa parte do dedo até hoje. E foi um transtorno pra mim, né?

eu coloquei o envelope e saí desesperada, ensanguentada porque eu achei até que tinha perdido

porque o corte foi profundo, né? $\mathbf{E u}$ achei que - só via sangue, achei que aquilo tivesse até cortado a ponta do dedo toda...e fiquei parada e falei assim: > "ai meu Deus! Meu Deus! Meu Deus!" <

Os exemplos acima evidenciam como o comportamento elocutivo é usado de forma estratégica pelo EUe no interior de seu ato de influência, sobretudo no que diz respeito à imagem que ele deseja encenar em seu ato de linguagem, isto é, ao processo de identificação que ele realiza ao tomar o turno no âmbito dessa situação de comunicação de Audiência de Conciliação. Assim, além de mostrar-se como vítima do 
ocorrido e, por conseguinte, como vítima do descaso do banco ao deixar um caixa de autoatendimento que lesa fisicamente as pessoas no espaço físico do Banco, o EUe também diz que ele é vítima ("eu coloquei o envelope e saí desesperada, ensanguentada"); em outras palavras, ele não só encena um ethos mostrado, mas também um ethos dito, para retomarmos aqui os termos de Maingueneau (2005; 2008).

A terceira estratégia empregada pelo EUe está relacionada às escolhas lexicais que este utiliza ao longo de seu ato de linguagem. Nessa audiência, a consumidora utiliza termos extremos em sua narrativa. Por exemplo, ao qualificar a situação como um "transtorno" e "traumatizante", o sujeito enunciador representa a si próprio através da imagem de alguém que passou por grande sofrimento, alguém que sofreu sérios danos físicos e psicológicos. Além disso, para tornar mais convincente seu relato, o EUe utiliza o sintagma adverbial "esse tempo todo" para mostrar a duração daquela situação e enfatizar seu sofrimento. Dessa forma, ele evidencia que o incômodo não foi somente no dia do ocorrido, mas persistia até o dia da audiência. Com isso, o sujeito enunciador constrói novamente o ethos de vítima.

Portanto, os vocábulos dos quais o EUe faz uso não são aleatórios; ao contrário, suas escolhas lexicais coadunam-se com o projeto de fala que ele tem em mente e, sobretudo, ao ethos que ele procura encenar.

Não só no momento inicial da situação de comunicação de Audiência de Conciliação o processo de construção/encenação do ethos é realizado. $\mathrm{Na}$ verdade, o processo de identificação ocorre ao longo de todo o texto. Contudo, como se trata de uma situação dialogal, o ethos inicialmente construído pode, por coerções do dizer dos demais sujeitos, ser modificado, visto que o sujeito enunciador pode querer adaptar seu dizer ao dito dos outros sujeitos como forma de aumentar a influência sobre estes.

$\mathrm{Na}$ audiência de conciliação analisada, observamos que o ethos inicialmente construído, no caso o ethos de vítima e de prejudicada, foi mantido ao longo de toda a audiência, inclusive quando há uma contraargumentação dos outros sujeitos envolvidos nessa mise en scène. Vejamos o exemplo (8): 


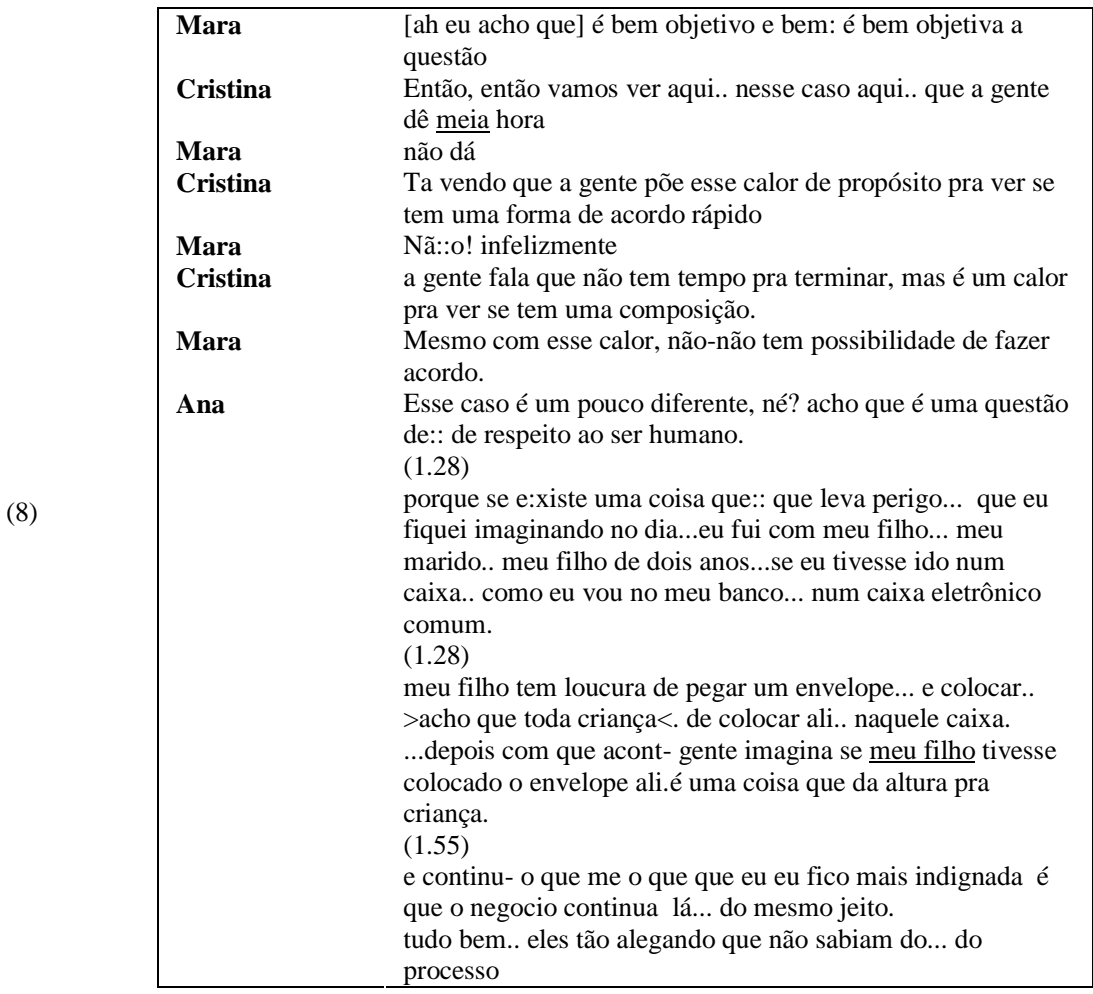

Pelo exemplo acima, percebemos que o acordo que o conciliador/mediador deseja estabelecer entre os participantes é negado por uma das partes, a saber o Banco (aqui representado por Mara e por Rita, a advogada). Nesse sentido, o sujeito enunciador, no seu papel de consumidor/reclamante, sofre uma coerção em seu ato de influência. Todavia, ele tenta manter seu projeto de fala, ou seja, faz crer que ele merece ser ressarcido, e, dessa forma, reconstrói o seu discurso de forma a criar esse efeito de sentido. No exemplo, observamos que ele narra novamente o fato ocorrido de um ponto de vista hipotético ("imagina se meu filho tivesse colocado o envelope ali. é uma coisa que dá altura pra criança"), na qual ele inclui outros seres na descrição/narração (no caso, o seu filho) para aumentar a influência sobre o destinatário. Ao realizar a 
racionalização narrativa, ele novamente constrói o ethos de vítima e de indignado ("eu fico mais indignada é que o negócio continua lá... do mesmo jeito") encenado ao longo de toda a audiência.

Então, podemos concluir que, na audiência de conciliação analisada, o EUe consumidor/reclamante, valendo-se estrategicamente da maneira como ele constrói a sua própria narrativa, do comportamento elocutivo e das escolhas lexicais, encena um ethos que coaduna-se com o seu projeto de fala: um ethos de vítima, que reforça a ideia de que seu problema é grave e que o ressarcimento que ele reivindica deve ser realizado. Portanto, através da análise, observamos que o processo de identificação dessa situação de comunicação funciona concomitantemente aos outros processos de tomada de fala, sobretudo ao processo de racionalização narrativa/descritiva.

\subsection{AUDIÊNCIA 02: CONTA DE ENERGIA ELÉTRICA}

Participaram dessa audiência a consumidora (Maria), os mediadores (Marcos e Iara) e a advogada do juizado (Luciana). A audiência foi motivada pela insatisfação da consumidora, proprietária de um imóvel, com um ex-inquilino, visto que este saiu de seu imóvel deixando uma conta de luz sem pagamento e essa conta estava sendo cobrada da reclamante, uma vez que o contrato de energia elétrica estava em nome dela. $\mathrm{O}$ reclamado não compareceu à audiência; dessa forma, ficaria a cargo do juiz dar a sentença - o que acontece quando, por algum motivo, o acordo não foi possível na audiência de conciliação. Entretanto, a consumidora já havia entrado com outro processo em outro local reivindicando um valor pela dívida da conta de energia elétrica e também do aluguel que o locatário não havia pagado. Como o réu não poderia ser julgado duas vezes pela mesma dívida, os mediadores aconselharam a reclamante a desistir da ação no juizado especial e esperar a sentença do juiz do outro processo, com a ação já em andamento.

Como estamos analisando a construção do ethos do consumidor/reclamante ao longo da situação de comunicação de Audiência de Conciliação, estamos, como no caso da primeira audiência, 
considerando o ato de linguagem do ponto de vista desse sujeito. Assim, sabemos que o mediador/conciliador aloca o turno ao consumidor/reclamante para que este narre o ocorrido e evidencie o motivo que o levou a procurar o Juizado especial e que, ao realizar tal procedimento enunciativo, ele constrói um determinado ethos que se coaduna com o seu projeto de fala e com o fazer (ato de influência) que ele deseja que o seu destinatário realize.

Em relação a essa audiência - denominada por nós Audiência da Conta de Energia Elétrica - percebemos que, no momento inicial, o EUe consumidor/reclamante procura, da mesma forma que o sujeito enunciador consumidor/reclamante da Audiência do Banco Poupa Fácil, encenar um ethos de vítima, de alguém que sofreu um prejuízo (neste caso, o EUe sofreu um prejuízo financeiro da parte de um inquilino de seu imóvel) e que, por isso, deseja ser ressarcido. Consideremos o exemplo (9):

\begin{tabular}{|ll|}
\hline Maria & $\begin{array}{l}\text { eu nem nesse endereço eu nunca morei, a casa lá eu alugava } \\
\text { pra ele }\end{array}$ \\
Iara & É tem um contrato aqui de locação da senhora \\
Maria & É, pois é e ele foi mexer no relógio \\
Iara & E esse valor de setecentos aqui \\
Maria & é da conta de luz e ele passou esse tempo todo, a conta ta \\
& aqui, ele não pagou porque ele cortaram a luz em vez dele \\
& pagar e a Cemig desligar o relógio ele chamou dizem que a \\
& ele chamou dois duas pessoa deve ser conhecida dele e fez \\
& uma ligação direta no relógio \\
\hline
\end{tabular}

Observamos que o EUe enuncia que a casa estava alugada para uma outra pessoa e que esta última deixou de pagar a conta de energia elétrica. Assim, ao narrar este fato, o sujeito enunciador, através do processo de identificação do ato de linguagem, mostra-se como vítima e prejudicado com relação ao ocorrido.

Entretanto, não só o ethos de vítima é encenado por este sujeito enunciador em específico. $\mathrm{O}$ ethos de ingênuo, de alguém que desconhece certos procedimentos, bem como de alguém que já foi, em outros momentos de sua vida, enganado por outras pessoas, é também mostrado (e em certo ponto, dito) por ele. Consideremos os excertos (10) e (11): 


\begin{tabular}{|c|c|c|}
\hline (10) & $\begin{array}{l}\text { Marcos } \\
\text { Maria } \\
\text { Marcos } \\
\text { Maria } \\
\text { Marcos }\end{array}$ & $\begin{array}{l}\text { É o grande problema aqui dona Maria } \\
\text { Ã? } \\
\text { Que a senhora alugou o imóvel e deixou a conta de energia } \\
\text { em nome [do locatário] } \\
\quad \text { [meu] } \\
\text { É da senhora, entendeu? Então praticamente a senhora ta } \\
\text { emprestando o nome da senhora pra ele, então o que ele } \\
\text { deixou ficou sob a responsabilidade da senhora esse é o } \\
\text { grande problema. } \\
\text { Quer dizer que é eu que vou ter que pagar mais essa conta? } \\
\text { Não, está em nome da senhora a dívida, né? [A Cemig não] } \\
\text { tem cont- a relação contratual com essa outra pessoa agora o } \\
\text { juiz pode decidir que a Cemig tenha que transferir pra ele. } \\
\text { Pois é, ue não é possível [se eu] tiver que pagar mais essa } \\
\text { conta dos outros eu num vou acreditar que vai ter mais mais } \\
\text { mais mais justiça nesse mundo }\end{array}$ \\
\hline
\end{tabular}

\begin{tabular}{|l|l|}
\hline Maria & $\begin{array}{l}\text { Mas eu não imaginava que ele ia mexer no relógio, eu só } \\
\text { queria ver ele que eu queria falar pra ele que se ele quisesse } \\
\text { roubar ele subisse no poste lá na rua e pegasse lá direto da } \\
\text { Cemig, não de mim, porque ta roubando de mim, uê, eu sou } \\
\text { pobre, eu num posso ficar pagando conta dos outros não. }\end{array}$ \\
\hline
\end{tabular}

No excerto (10), observamos que, ao dizer "não é possível (...) pagar mais essa conta dos outros", o EUe, através do uso do quantificador mais, deixa subentendido que esta não é a primeira vez que ele tem um prejuízo como este. Assim, ele constrói uma imagem de pessoa ingênua e inocente que, por mais de uma vez, teve que pagar uma conta que não é dele. Já no exemplo (11), o EUe se justifica dizendo que não imaginava que o inquilino em questão mexeria no relógio, construindo, aqui também, um ethos de uma pessoa ingênua, de boa índole e que confia no outro. Em seguida, ele explicitamente diz: "Eu sou pobre, eu não posso ficar pagando conta dos outros não", o que nos permite concluir que, nesse momento, ele constrói um ethos dito de pessoa pobre e injustiçada. Nesse sentido, ele se autorrepresenta como alguém com baixo poder aquisitivo, incapaz de pagar aquela conta de luz, e comprova sua posição de vítima. Logo, os outros ethé que este EUe consumidor/reclamante encena (ethos de pessoa ingênua, ethos de pessoa com baixo poder aquisitivo, ethos de pessoa injustiçada) auxiliam e se coadunam com o ethos central que ele tenta construir ao longo de toda a audiência: o ethos de vítima.

No que tange às estratégias de encenação discursiva do ethos, estas, na audiência em análise, são as mesmas da primeira audiência 
analisada, a Audiência Banco Poupa Fácil. Assim, o EUe consumidor/reclamante vale-se da própria racionalização narrativa/descritiva como primeira estratégia de construção dos seus ethé: ele narra os fatos de forma a se mostrar como vítima do ocorrido e, sobretudo, do inquilino; como uma pessoa ingênua que acredita facilmente nos outros e que, por isso, é passada para trás; como uma pessoa de baixo poder aquisitivo; e como uma pessoa injustiçada.

O comportamento elocutivo é também utilizado de forma estratégica por este EUe: ele narra sua história de forma elocutiva para não só dizer que ele é uma pessoa vitimizada, pobre, injustiçada e ingênua, mas sobretudo se mostrar como tal. Os exemplos (12) e (13) evidenciam a presença do comportamento elocutivo ao longo do texto:

(12) eu não tenho condição de ficar pagando conta dos outros.

(13) Tô pagando a OI também, setenta re-parcelou porque a muié não pagava nem o ( ) nem a linha. Fiz assinatura pra ela tô pagando setenta reais de de parcela. A gente fica revoltado, na hora de de de fazer da justiça eles sempre sempre não tem jeito de pegar eles a gente.

As escolhas lexicais são também utilizadas de maneira estratégica pelo EUe. Através dos vocábulos empregados, ele não somente diz que é de uma tal forma (ethos dito), mas se mostra (ethos mostrado) como sendo de tal maneira.

Portanto, na audiência Conta de Energia Elétrica, observamos que, além do ethos de vítima e injustiçado, o EUe, no seu papel de consumidor/reclamante desta situação de comunicação, constrói um ethos de pessoa ingênua e um ethos de pessoa com baixo poder aquisitivo. Esses últimos ethé coadunam-se com o ethos central, o ethos de vítima, de forma a aumentar a influência sobre o destinatário. Esses ethé são construídos por meio de algumas estratégias discursivas:

a) pela narrativa/relato do fato;

b) pelo comportamento elocutivo; e

c) pela escolha lexical.

Tais estratégias permitem encenar os ethé levantados, mas também fazem com que EUe não só diga (ethos dito) que ele é de tal maneira, mas permitem que ele se mostre como sendo dessa forma 
(ethos mostrado). Assim, considerando o fazer geral que o EUe deseja que o TUd realize, no caso um fazer crer que seu problema merece atenção e que, por ter sido prejudicado por alguém/algo, ele deve se ressarcido, a construção do ethos, realizada através do processo de identificação do ato de linguagem, coaduna-se com esse fazer, aumentando, dessa forma, a força de influência do seu discurso.

Ao compararmos as duas audiências analisadas, observamos que os sujeitos enunciadores consumidores/reclamantes dessa situação de comunicação procuram construir, de uma maneira geral, um ethos de vítima do ocorrido. Embora o EUe possa encenar outros ethé, estes, de certa forma, vão ao encontro do ethos central, aumentando assim seu poder de influência. Logo, considerando o contrato de comunicação da situação de Audiência de Conciliação, podemos concluir que o ethos de vítima encenado pelos EUe analisados vão ao encontro da própria finalidade do contrato desta situação, bem como ao projeto de fala que tais sujeitos enunciadores têm em mente: o consumidor/reclamante objetiva, com esta situação, mostrar que o seu problema é digno de atenção e que ele deve ser ressarcido. Assim, o processo de identificação é, juntamente com os demais processos de tomada de palavra (processo de regulação, processo de dramatização e processo de racionalização), um dos elementos que permitem realizar o projeto de fala e a finalidade contratual dessa situação de comunicação; tais processos procuram levar o TUd a compartilhar uma determinada posição e a realizar certos fazeres: fazer crer, fazer aderir, fazer emocionar. Logo, ao representar a si próprio através de sua encenação discursiva, o EUe deseja fazer-crer ao TUd que ele é de uma certa forma, isto é, que ele possui um ethos específico.

\section{CONSIDERAÇÕES FINAIS}

O presente trabalho apresentou o resultado de um estudo do ethos discursivo do consumidor/reclamante em duas Audiências de Conciliação, gravadas em agosto de 2008 na cidade de Belo Horizonte/MG. Nesse sentido, procuramos demonstrar como tal sujeito, nesta situação de comunicação, constrói um ethos que vai ao 
encontro tanto da finalidade do contrato de comunicação que liga os parceiros da troca, a saber, o consumidor/reclamante, o mediador/conciliador e o fornecedor/reclamado, como do projeto de fala que o sujeito enunciador tem em mente ao tomar a palavra e procurar exercer a influência sobre o destinatário do ato de linguagem.

Nossa análise demonstrou que, embora o sujeito enunciador possa encenar outros ethé, a representação de si próprio construída através do ato de linguagem, de uma maneira geral, é a de um sujeito vítima de determinada ocorrência. Para construir esse ethos de vítima (assim como os outros ethé: ethos de injustiçado, de pobreza e de ingenuidade), o sujeito enunciador (EUe), no seu papel de consumidor/reclamante desta situação de comunicação, utiliza as seguintes estratégias:

a) narrativa do fato ocorrido de forma a se mostrar como o sujeito vítima da situação;

b) uso do comportamento elocutivo que, pelo fato de mostrar o ponto de vista subjetivo do sujeito enunciador a respeito do dito, permite que o EUe se insira no dizer e se coloque como portador de tal identidade, além de se mostrar como tal; e

c) escolha lexical, através da qual o EUe seleciona palavras que de modo algum são aleatórias, mas que, ao contrário, auxiliam a construção do ethos de vitimização nas duas audiências analisadas.

$\mathrm{Na}$ primeira audiência analisada, a consumidora reivindica uma indenização por danos físicos e morais; por isso, há em seu discurso a construção de uma imagem de si mesma que a coloca como uma pessoa que passou por muito sofrimento, angústia, transtorno, ou seja, ela cria um ethos de vítima a fim de conseguir o ressarcimento pelos prejuízos sofridos. Na segunda, a reclamante deseja que seu ex-inquilino pague a conta de luz que ficou pendente quando morava em seu imóvel. Para isso, ela constrói uma imagem de pessoa pobre, inocente, que não tem condições de pagar aquela conta. Assim, a reclamante cria um ethos de pobreza e, consequentemente, de vítima, a fim de não precisar pagar aquela dívida. 
Além disso, nossa análise demonstrou que o processo de identificação do sujeito enunciador não age sozinho na encenação linguageira. Ao contrário, os demais processos - processo de regulação, processo de dramatização e processo de racionalização - agem concomitantemente ao processo de identificação, o que, em termos de uma problemática de influência, permite aumentar a força persuasiva do ato de linguagem, assim como arquitetar de forma estratégica o projeto de fala do EUe. Nas audiências analisadas, percebemos que o processo de racionalização narrativa/descritiva, por exemplo, funcionou lado a lado do processo de identificação, uma vez que, à medida que o EUe narrava sua história e o ocorrido, ele construía e encenava o ethos de vítima a respeito do qual comentamos anteriormente.

Portanto, um estudo do ethos discursivo em textos como esses é bastante promissor na medida em que ele pode nos revelar os implícitos discursivos, sobretudo em relação à maneira como o enunciador constrói a sua imagem para levar o seu destinatário a acreditar que o que ele diz é realmente o que aconteceu, isto é, levar o TUd a crer que ele, de fato, foi vítima do fato ocorrido.

\section{REFERÊNCIAS}

ARISTÓTELES. Retórica. Tradução de Marcelo Silvano Madeira. São Paulo: Rideel, 2007.

AMOSSY, R. Da noção retórica de ethos à análise do discurso. In:

Imagens de si no discurso: a construção do ethos. Tradução Dílson Ferreira da Cruz, Fabiana Komesu e Sírio Possenti. São Paulo: Contexto, 2005a, p. 9-28.

. O ethos na intersecção das disciplinas: retórica, pragmática e sociologia

dos campos. In: . Imagens de si no discurso: a construção do ethos. Tradução de Dílson Ferreira da Cruz, Fabiana Komesu e Sírio Possenti. São Paulo: Contexto, 2005b. p. 119-144.

CHARAUDEAU, P. Grammaire du sens et de l'expression. Paris: Hachette, 1992.

Discurso político. Tradução de Angela M. S. Corrêa. São Paulo: Contexto, 2006. 
L'argumentation dans une problématique d'influence. Argumentation et Analyse du Discours, n. 1, 2008a. Disponível em:

<http://aad.revues.org/index193.html>. Acesso em: 12 nov. 2008.

. Linguagem e discurso - modos de organização. Coordenação da equipe de tradução Ângela M. S. Corrêa e Ida Lúcia Machado. São Paulo: Contexto, 2008b.

EGGS, E. Ethos aristotélico, convicção e pragmática moderna. In. AMOSSY, R. (Org.) Imagens de si no discurso: a construção do ethos. Tradução de Dílson Ferreira da Cruz, Fabiana Komesu e Sírio Possenti. São Paulo: Contexto, 2005. p. 29-56.

MAINGUENEAU, D. Ethos, cenografia, incorporação. In: AMOSSY, R. (Org.). Imagens de si no discurso: a construção do ethos. Tradução de Dílson Ferreira da Cruz, Fabiana Komesu e Sírio Possenti. São Paulo: Contexto, 2005. p. 69-92. . A noção de ethos discursivo. In: MOTTA, A. R.; SALGADO, L. Ethos discursivo. São Paulo: Contexto, 2008. p. 11-32.

Recebido em: 01/08/11. Aprovado em: 26/03/12.

Title: $A$ study of the discursive ethos in conciliation hearings

Authors: Elaine Luzia da Silva, Leonardo Coelho Corrêa Rosado, Mônica Santos de Souza Melo

Abstract: This study investigates the main strategies of ethos construction of the consumer-enunciator subject that emerges in the participants' discursive production in a Conciliation Hearing in a Brazilian Small Claims Court (Juizado Especial de Relações de Consumo) from a city in Minas Gerais state. For this, we selected two Conciliation Hearings, which were transcribed and analyzed from the perspective of Semiolinguistics Theory of Patrick Charaudeau. Data analysis showed that during the analyzed audiences the ethos of victim by the consumer is built through some discursive strategies which are not random; on the contrary, the strategies used are consistent with the speech project that the consumer has in mind and, above all, the ethos that he desires to perform.

Keywords: Conciliation hearings. Discursive ethos. Semiolinguistics.

Título: Un estudio del ethos discursivo en audiencias de conciliación

Autores: Elaine Lužia da Silva, Leonardo Coelho Corrêa Rosado, Mônica Santos de Souza Melo

Resumen: El presente artículo investiga las principales estrategias de construcción del ethos del sujeto enunciador-consumidor que emergen en la producción discursiva de los participantes de Audiencias de Conciliación, de un Juzgado Especial Civil de Relaciones de Consumo de una ciudad minera. Para tanto, seleccionamos dos Audiencias de Conciliación, que fueron transcriptas y analizadas a partir de la teoría Semiolingüistica de Patrick Charaudeau. El análisis de los datos demostró que, a lo largo de las audiencias analizadas, el ethos de victima del consumidor/reclamante es representado a través de algunas estrategias discursivas, las cuales no son aleatorias; al contrario, las estrategias utilizadas son consistentes con el proyecto de habla que el consumidor tiene en mente y, sobre todo, al ethos que él busca representar. Palabras-clave: Audiencias de Conciliación. Ethos discursivo. Semiolingüistica. 